\title{
Ex vivo and in vivo T cell-depleted allogeneic stem cell transplantation in patients with acute myeloid leukemia in first complete remission resulted in similar overall survival: on behalf of the ALWP of the EBMT and the MSKCC
}

Florent Malard ${ }^{1,2^{*}}$ (D), Myriam Labopin ${ }^{1}$, Christina Cho ${ }^{3,4}$, Didier Blaise ${ }^{5}$, Esperanza B. Papadopoulos ${ }^{3,4}$, Jakob Passweg ${ }^{6}$, Richard O'Reilly, ${ }^{7,}$, Edouard Forcade ${ }^{9}$, Molly Maloy ${ }^{3}$, Liisa Volin ${ }^{10}$, Hugo Castro-Malaspina ${ }^{3,4}$, Yosr Hicheri ${ }^{11}$, Ann A. Jakubowski ${ }^{3,4}$, Corentin Orvain ${ }^{12}$, Sergio Giralt ${ }^{3,4}$, Mohamad Mohty ${ }^{1,2}$, Arnon Nagler ${ }^{13,14}$ and Miguel-Angel Perales $3,4,15^{*}$

\begin{abstract}
Background: Graft-versus-host disease (GVHD) is one of the leading causes of non-relapse mortality and morbidity after allogeneic hematopoietic stem cell transplantation (allo-HCT).

Methods: We evaluated the outcomes of two well-established strategies used for GVHD prevention: in vivo T cell depletion using antithymocyte globulin (ATG) and ex vivo T cell depletion using a CD34-selected (CD34+) graft. A total of 525 adult patients (363 ATG, 162 CD34+) with intermediate or high-risk cytogenetics acute myeloid leukemia (AML) in first complete remission (CR1) were included. Patients underwent myeloablative allo-HCT using matched related or unrelated donors.
\end{abstract}

Results: Two-year overall survival estimate was $69.9 \%(95 \% \mathrm{Cl}$, 58.5-69.4) in the ATG group and $67.6 \%(95 \% \mathrm{Cl}, 60.3-74.9)$ in the CD34+ group $(p=0.31)$. The cumulative incidence of grade $I I-I V$ acute GVHD and chronic GVHD was higher in the ATG cohort [HR 2.0 (95\% Cl 1.1-3.7), $p=0.02$; HR 15.1 (95\% Cl 5.3-42.2), $p<0.0001]$. Parameters associated with a lower GVHD-free relapse-free survival (GRFS) were ATG [HR $1.6(95 \% \mathrm{Cl} 1.1-2.2), p=0.006]$, adverse cytogenetic [HR 1.7 (95\% Cl 1. $3-2.2), p=0.0004]$, and the use of an unrelated donor [HR $1.4(95 \% \mathrm{Cl} 1.0-1.9), p=0.02]$. There were no statistical differences between ATG and CD34+ in terms of relapse [HR 1.52 (95\% Cl 0.96-2.42), $p=0.07]$, non-relapse mortality [HR $0.96(95 \% \mathrm{Cl}$ 0.54-1.74), $p=0.90$ ], overall survival [HR 1.43 (95\% Cl 0.97-2.11), $p=0.07$ ], and leukemia-free survival [HR 1.25 (95\% Cl 0.88-1. 78), $p=0.21$. Significantly, more deaths related to infection occurred in the CD34+ group $(16 / 52 \mathrm{vs.} 19 / 112, p=0.04)$.

Conclusions: These data suggest that both ex vivo CD34-selected and in vivo ATG T cell depletion are associated with a rather high OS and should be compared in a prospective randomized trial.

Keywords: Acute myeloid leukemia, T cell depletion, CD34-selected graft, Antithymocyte globulin, Allogeneic hematopoietic cell transplantation

\footnotetext{
*Correspondence: malardf@yahoo.fr; peralesm@mskcc.org

'Service d'Hématologie Clinique et Thérapie Cellulaire, AP-HP, Hôpital

Saint-Antoine, Paris F-75012, France

${ }^{3}$ Adult Bone Marrow Transplantation Service, Memorial Sloan Kettering

Cancer Center, New York, NY, USA

Full list of author information is available at the end of the article
}

(c) The Author(s). 2018 Open Access This article is distributed under the terms of the Creative Commons Attribution 4.0 International License (http://creativecommons.org/licenses/by/4.0/), which permits unrestricted use, distribution, and reproduction in any medium, provided you give appropriate credit to the original author(s) and the source, provide a link to the Creative Commons license, and indicate if changes were made. The Creative Commons Public Domain Dedication waiver (http://creativecommons.org/publicdomain/zero/1.0/) applies to the data made available in this article, unless otherwise stated. 


\section{Background}

Allogeneic hematopoietic stem cell transplantation (allo-HCT) is the only potentially curative post-remission consolidation treatment for high-risk acute myeloid leukemia (AML) patients [1, 2]. However, preparative regimen-related toxicities and graft-versus-host disease (GVHD) have limited its widespread use. In particular, chronic GVHD (cGVHD) remains the leading cause of late non-relapse mortality (NRM) and morbidity after allo-HCT. Furthermore, the increasing use of G-CSF mobilized peripheral blood stem cells (PBSC) [3], a well-identified risk factor for chronic GVHD $[4,5]$, is associated with an increased incidence of cGVHD $[3,6]$. Therefore, identification of the most effective prevention of GVHD is required to improve patients' outcome after allo-HCT, particularly in the setting of PBSC transplantation.

In vivo graft manipulation with antithymocyte globulin (ATG) [7-13] or alemtuzumab [14] and ex vivo graft manipulation with CD34 selection and $\mathrm{T}$ cell depletion [15-19] are strategies that are associated with lower rates of chronic GVHD. Since 2000, five phase III randomized trials have investigated the efficacy of rabbit ATG for GVHD prophylaxis in patients who received myeloablative (MAC) allo-HCT from unrelated or HLA-identical matched donors [713]. In all these studies, the use of ATG was associated with a protective effect against cGVHD and in all but one study [12], overall survival (OS) and progression-free survival were not significantly affected [13]. Therefore, in vivo $\mathrm{T}$ cell depletion using ATG is now considered a standard for GVHD prevention after PBSC transplantation using related HLA-identical or unrelated donors in many centers. On the other hand, several studies have shown that the use of ex vivo T cell-depleted (TCD) grafts combined with ATG significantly reduces the risk of GVHD without the need for post-transplant immunosuppression [16, 20, 21]. Although several different approaches for $\mathrm{T}$ cell depletion of the allograft have been used over the years, more recently, removal of $\mathrm{T}$ cells from the graft has routinely been performed through positive selection of CD34+ cells using immunomagnetic beads [22]. To date, no study has compared outcomes in AML patients after myeloablative allo-HCT with ex vivo TCD using CD34 selection or in vivo TCD using ATG. To compare the efficacy of both approaches, we retrospectively evaluated the outcomes of patients with intermediate or high-risk AML in first complete remission (CR1) who underwent myeloablative allo-HCT with either in vivo TCD with ATG within the European group for Blood and Marrow Transplantation (EBMT) centers or ex vivo TCD CD34 selected (CD34+) graft at the Memorial Sloan Kettering Cancer Center (MSKCC).

\section{Methods}

\section{Study design and data collection}

This retrospective multicenter analysis was performed and approved by the Acute Leukemia Working Party (ALWP) of the EBMT group registry and the institutional review board of the MSKCC. A list of the EBMT participating centers is available online (Additional file 1). The study included all adult patients (age $>18$ years) with AML, with intermediate or high-risk cytogenetic, in first morphological $\mathrm{CR}$, who received an in vivo or ex vivo T cell-depleted myeloablative allo-HCT from an HLA matched related (MRD) or unrelated (UD) donor using a peripheral blood stem cell graft between 2005 and 2015. Cytogenetics were classified according to the European Leukemia Net [23]. All allografts were obtained from HLA-A-, HLA-B-, HLA-C-, and HLA-DRB1-matched donors. All patients underwent myeloablative conditioning. Patients at MSKCC received ex vivo TCD graft (CD34+ group, $n=162$ ) after conditioning with one of the following preparative regimens as previously reported: (1) i.v. busulfan $(\mathrm{Bu}) 0.8 \mathrm{mg} / \mathrm{kg} / \mathrm{dose}$ for 10 or 12 doses over a 4-day period, melphalan $70 \mathrm{mg} / \mathrm{m}^{2} /$ day for 2 days, and i.v. fludarabine (Flu) $25 \mathrm{mg} / \mathrm{m}^{2} /$ day for 5 days $(n=107)$; (2) hyperfractionated total body irradiation (TBI) 13.75 Gy over 4 days followed by i.v. thiotepa $5 \mathrm{mg} /$ $\mathrm{kg} /$ day for 2 days and i.v. cyclophosphamide (Cy) $60 \mathrm{mg} /$ $\mathrm{kg} /$ day for 2 days $(n=45)$ or i.v. Flu $25 \mathrm{mg} / \mathrm{m}^{2} /$ day for 5 days $(n=10)$. Peripheral blood grafts underwent CD34 cell selection using the ISOLEX 300i magnetic cell selection system (Baxter, Deerfield, IL), followed by sheep red blood cell-rosette depletion (Isolex-E, $n=53$ ); or CD34+ selection using the CliniMACS CD34 Reagent System (Miltenyi Biotech, Gladbach, Germany) $(n=109)$. The two approaches provide a similar level of $\mathrm{T}$ cell depletion ( $\log 105.3$ with Isolex-E vs. 5.1 with CliniMACS, Jakubowski et al., in preparation). All patients received equine ATG $(30 \mathrm{mg} / \mathrm{kg}$ total dose, $n=12$ ) or rabbit ATG (thymoglobulin $5 \mathrm{mg} / \mathrm{kg}$ total dose, $n=143$ ) to prevent graft rejection, except for those patients receiving a transplant from an HLA-matched related donor and conditioned with hyperfractionated TBI, thiotepa, and Flu $(n=7)$. No GVHD prophylaxis was administered post-transplantation.

Within the EBMT centers, patients received unmodified grafts and in vivo $\mathrm{T}$ cell depletion using rabbit ATG (group ATG, $n=363$ ) after one of the following preparative regimens: (1) $\mathrm{Bu} 9.6-12.8 \mathrm{mg} / \mathrm{kg}$ total dose and i.v. fludarabine $(n=173)$, (2) Bu 9.6-12.8 mg/kg total dose and i.v. Cy $100-120 \mathrm{mg} / \mathrm{kg}$ total dose $(n=129)$, or (3) high-dose TBI and i.v. Cy 100-120 mg/kg total dose ( $n$ $=61)$. Patients received either thymoglobulin $(n=233)$ or grafalon (formerly ATG-fresenius, $n=130$ ) for prevention of graft rejection and of GVHD. These patients received post-HCT GVHD prophylaxis consisting of cyclosporine alone $(n=62)$ or in combination with methotrexate $(n=213)$ or mycophenolate mofetil $(n=$ 
$60)$, tacrolimus in combination with methotrexate $(n=2)$ or sirolimus $(n=10)$ or other combinations $(n=16)$.

Supportive care and antimicrobial prophylaxis were administered according to standard guidelines and include infection prophylaxis for Pneumocystis jirovecii and herpes virus. All patients were assessed at least once per week for cytomegalovirus (CMV) and Epstein-Barr virus (EBV) reactivation in the peripheral blood by polymerase chain reaction, to initiate preemptive therapy [24].

\section{Statistical analysis}

Endpoints included OS, leukemia-free survival (LFS), cumulative incidence of relapse, NRM, acute and chronic GVHD, and refined GVHD-free relapse-free survival (GRFS) [25]. All outcomes were measured from the time of allo-HCT. OS was based on death, regardless of the cause. LFS was defined as survival with no evidence of relapse. OS and LFS rates were calculated by the Kaplan-Meier estimator. Cumulative incidence functions were used to estimate the probabilities of acute and chronic GVHD, NRM, relapse, and GRFS to accommodate competing risks. NRM and relapse were the competing risks for each other. Patients alive without relapse were censored at the time of last contact. For acute and chronic GVHD, the competing risk was death without the event. For refined GRFS, the events were relapse, grade III-IV acute GVHD, or extensive cGVHD and the competing risk was death without the events [25]. Acute GVHD was defined according to the standard criteria [26]. Due to the retrospective nature of this analysis, NIH cGVHD classification [27] was not available for EBMT centers; therefore, Shulman et al. classification (limited versus extensive) [28] was used for all patients.

Patients' characteristics were compared between the CD34+ and the ATG groups using the chi-square test or the Fisher exact test for categorical variables and the Mann-Whitney test for continuous data. Univariate analyses were performed using the log-rank test for OS and LFS and Gray's test for cumulative incidences. Chronic GVHD was analyzed as a time-dependent variable. For multivariate regression, a Cox proportional hazards model was built. Impact of age was analyzed per decade. Results were expressed as hazard ratio (HR) with 95\% confidence interval (CI). All tests were two-sided and the type- 1 error rate was fixed at 0.05 . Statistical analyses were performed with SPSS 19 (SPSS Inc. /IBM, Armonk, NY) and R 3.0.1 (R Development Core Team, Vienna, Austria) software packages.

\section{Results}

\section{Patient and donor characteristics}

Patients and transplant characteristics are summarized in Table 1. Patients, in the CD34+ group who were significantly older, were more likely to have a matched related donor and a Karnofsky performance status < $90 \%$ compared to the ATG group. There were no statistically significant differences between groups regarding donor and patient gender, CMV serological status, and cytogenetic risk factor. The median follow-up among surviving patients was 35.4 (range, 2-139) months and was significantly longer in the CD34+ group, 58 (range, 6-139) months, compared to that in the ATG group, 24.5 (range, $2-131)$ months $(p<0.001)$. As a result, all patients were censored at 2 years for the comparison between groups.

\section{Engraftment}

Engraftment was achieved in $362 / 363$ patients $(99.7 \%)$ in the ATG and 159/162 (98.1\%) in the CD34+ group ( $p=$ 0.06 ). The median time to neutrophil recovery was significantly longer in the ATG group: 16 (range, 6-34) days compared with 10 (range, 8-20) days in the CD34+ group $(p<0.0001)$.

\section{Overall survival and leukemia-free survival}

Univariate and multivariate analyses of transplantation-related events are summarized in Tables 2 and 3, respectively. The Kaplan-Meier estimate of OS at 2 years was $63.9 \%$ (95\% CI, 58.5-69.4) in the ATG group and $67.6 \%(95 \% \mathrm{CI}, 60.3-74.9)$ in the CD34+ group $(p=$ 0.31, Fig. 1a). In multivariate analysis, there was no significant difference in OS between the TBI group and the $\mathrm{Bu}$ group (HR, 1.43; 95\% CI, 0.97-2.11; $p=0.07$ ). The only parameters with a significant impact on OS in multivariate analysis were patients' age and cytogenetic status. OS was significantly lower in patients with poor as compared to intermediate-risk cytogenetics (HR, 1.16; 95\% CI, 1.11-2.19; $p=0.009)$ and in older patients (HR, 1.15; 95\% CI, 1.00$1.34 ; p=0.049$ ). The Kaplan-Meier estimate of LFS at 2 years was $57.9 \%(95 \% \mathrm{CI}, 52.4-63.4)$ in the ATG group and $61.0 \%$ (95\% CI, 53.4-68.5) in the CD34+ group ( $p=0.29$, Fig. 1b). In multivariate analysis, there was no significant difference in LFS between the ATG and the CD34+ groups (HR, 1.25; 95\% CI, 0.88-1.78; $p=0.21$ ). The only parameter with a significant impact on LFS in multivariate analysis was cytogenetic status. LFS was significantly lower in patients with poor compared to those with intermediate risk cytogenetics (HR, 1.70; 95\% CI, 1.26-2.31).

\section{Relapse}

At 2 years, the cumulative incidence of relapse was $30.0 \%$ (95\% CI, 24.9-35.2) in the ATG group and 21.6\% (95\% CI, 15.6-28.3) in the CD34+ group ( $p=$ 0.03 , Fig. 1c). In multivariate analysis, there was a trend toward a higher cumulative incidence of relapse in the ATG group (HR, 1.52; 95\% CI, 0.96-2.42; $p=$ $0.07)$. The only parameter with a significant impact on relapse incidence in multivariate analysis was cytogenetic risk status: relapse was significantly increased 
Table 1 Study population characteristics

\begin{tabular}{|c|c|c|c|}
\hline Characteristic (\%) & ATG $(N=363)$ & CD34 $(N=162)$ & $p$ \\
\hline Patient age, median (range) & $46(19-77)$ & $58(20-73)$ & $<0.001$ \\
\hline Year of transplant & $2012(2005-2015)$ & $2011(2005-2015)$ & \\
\hline \multicolumn{4}{|l|}{ Patient gender } \\
\hline Male & $200(55 \%)$ & $90(56 \%)$ & \multirow[t]{2}{*}{0.92} \\
\hline Female & $163(45 \%)$ & $72(44 \%)$ & \\
\hline Female donor to male patient & $65(18 \%)$ & $37(23 \%)$ & 0.19 \\
\hline \multicolumn{4}{|l|}{ Karnofsky performance scale } \\
\hline$\geq 90 \%$ & $258(76 \%)$ & $100(63 \%)$ & \multirow[t]{3}{*}{0.003} \\
\hline$<90 \%$ & $83(24 \%)$ & $59(37 \%)$ & \\
\hline unknown & 22 & 3 & \\
\hline \multicolumn{4}{|l|}{ CMV serologic status } \\
\hline Seronegative donor-recipient pair & $114(32 \%)$ & $49(33 \%)$ & 0.4 \\
\hline Time from diagnosis to transplant, months (range) & $4.9(1.9-14.3)$ & $4.3(1.7-11.4)$ & 0.001 \\
\hline \multicolumn{4}{|l|}{ Cytogenetic } \\
\hline Intermediate & $259(71 \%)$ & $112(69 \%)$ & \multirow[t]{2}{*}{0.61} \\
\hline Poor & $104(29 \%)$ & $50(31 \%)$ & \\
\hline \multicolumn{4}{|l|}{ Donor } \\
\hline Matched related donor & $118(33 \%)$ & $73(45 \%)$ & \multirow[t]{2}{*}{0.006} \\
\hline Unrelated donor & $245(67 \%)$ & $89(55 \%)$ & \\
\hline \multicolumn{4}{|l|}{ Conditioning regimen } \\
\hline Busulfan + fludarabine & $173(48 \%)$ & 0 & \multirow[t]{6}{*}{$<0.0001$} \\
\hline Busulfan + cycloclophosphamide & $129(36 \%)$ & 0 & \\
\hline TBI + cyclophosphamide & $61(17 \%)$ & 0 & \\
\hline Busulafan + fludarabine + melphalan & 0 & $107(66 \%)$ & \\
\hline TBI + cycloclophosphamide + thiotepa & 0 & $45(28 \%)$ & \\
\hline TBI + fludarabine + thiotepa & 0 & $10(6 \%)$ & \\
\hline \multicolumn{4}{|l|}{ GVHD prophylaxis } \\
\hline CsA & $62(17 \%)$ & - & \multirow[t]{6}{*}{-} \\
\hline $\mathrm{Cs} A+M M F$ & $210(58 \%)$ & - & \\
\hline $\operatorname{Cs} A+M T X$ & $65^{*}(18 \%)$ & - & \\
\hline Tacrolimus + sirolimus & $10(3 \%)$ & - & \\
\hline PT Cy & $5(1 \%)$ & - & \\
\hline Others & $11(3 \%)$ & - & \\
\hline \multicolumn{4}{|l|}{ Antithymocyte globuline } \\
\hline Thymoglobulin (median dose, mg/kg; range) & $233(5 ; 5-7.5)$ & $143(5 ; 2-5)$ & \\
\hline Grafalon, (median dose, mg/kg; range) & $130(35 ; 8-60)$ & 0 & \\
\hline Equine ATG, (median dose, mg/kg; range) & 0 & $12(30 ; 15-30)$ & - \\
\hline \multicolumn{4}{|l|}{ Cells doses } \\
\hline CD34+ cells, $\times 10^{6} / \mathrm{kg}$ (range) & $6.13(1.64-21.2)$ & $8.18(1.1-31.2)$ & $<0.0001$ \\
\hline CD $3+$ cells, $\times 10^{6} / \mathrm{kg}$ (range) & $213(1.13-643)$ & $0.002(0-0.063)$ & $<0.0001$ \\
\hline
\end{tabular}

Abbreviations: TBI total body irradiation, GVHD graft versus host disease, CsA ciclosporine A, MMF mycophenolate mofetil, PT Cy post-transplant cyclophosphamide, $N A$ not available

*In two patients, CsA have been substituted by tacrolimus 
Table 2 Transplant-related events univariate analysis

\begin{tabular}{|c|c|c|c|}
\hline Characteristic (\%) & $\operatorname{ATG}(N=363)$ & CD34 $(N=162)$ & $p$ \\
\hline OS at 2 years, months $(95 \% \mathrm{Cl})$ & $69.9(58.5-69.4)$ & $67.6(60.3-74.8)$ & 0.31 \\
\hline LFS at 2 years, months $(95 \% \mathrm{Cl})$ & $57.9(52.4-63.4)$ & $61.0(53.4-68.5)$ & 0.29 \\
\hline Cumulative incidence of NRM at 2 years (95\% Cl) & $12.1(8.9-15.9)$ & $17.4(12.0-23.6)$ & 0.16 \\
\hline Cumulative incidence of relapse at 2 years ( $95 \% \mathrm{Cl})$ & $30.0(24.9-35,2)$ & $21.6(15.6-28.3)$ & 0.03 \\
\hline Cumulative incidence of grade II-IV aGVHD at 100 days (95\% CI) & $21.2(17.1-25.6)$ & $11.3(7.0-16.8)$ & 0.006 \\
\hline Cumulative incidence of grade III-IV aGVHD at 100 days (95\% CI) & $6.2(4-9.1)$ & $1.3(0.2-4.1)$ & 0.01 \\
\hline Cumulative incidence of cGVHD at 1 year (95\% Cl) & $27.6(22.8-32.6)$ & $2.5(0.8-5.8)$ & $<0.0001$ \\
\hline Cumulative incidence of extensive cGVHD at 1 year (95\% Cl) & $11.3(8.0-15.1)$ & $2.5(0.8-5.8)$ & 0.001 \\
\hline Cumulative incidence of GRFS at 2 years (95\% Cl) & $47.0(41.4-52.5)$ & $59.1(51.5-66.7)$ & 0.003 \\
\hline \multicolumn{4}{|l|}{ Cause of death } \\
\hline GVHD & $14(12 \%)$ & $5(10 \%)$ & \multirow[t]{4}{*}{0.36} \\
\hline Infections & $19(17 \%)$ & $16(30 \%)$ & \\
\hline Other & $20(18 \%)$ & $7(14 \%)$ & \\
\hline Relapse/progression & $59(53 \%)$ & $24(46 \%)$ & \\
\hline
\end{tabular}

Abbreviations: OS overall survival, CI confidence interval. LFS leukemia-free survival, NRM non-relapse mortality, aGVHD acute graft-versus-host disease, $c G V H D$ chronic graft versus host disease

in patients with poor compared to intermediate risk cytogenetics (HR, 2.10; 95\% CI, 1.46-3.03; $p<0.0001$ ). Therefore, a subgroup analysis was performed to separately analyze patients with intermediate and high-risk cytogenetic. In patients with intermediate risk cytogenetic, the 2-year cumulative incidence of relapse was significantly higher in the ATG group compare to the CD34+ group [25.0\% (95\% CI, 19.5$30.6)$ versus $11.6 \%$ (95\% CI, 6.5-18.4)]. In multivariate analysis, TCD approach was the only parameter with an impact on relapse with a significantly higher cumulative incidence of relapse in the ATG group (HR, 2.42; 95\% CI, 1.22-4.78; $p=0.01$ ). In contrast, in the subgroup of patients with high-risk cytogenetic, TCD approach has no impact on the cumulative incidence of relapse $[42.7 \%(95 \% \mathrm{CI}, 32.1-53.0)$ in the ATG group versus $44.0 \%$ (95\% CI, 29.9-57.3)].

\section{Graft-versus-host disease}

The day-100 cumulative incidence of grade II-IV and grade III-IV aGVHD were significantly higher in the ATG group, being 21.2\% (95\% CI, 17.1-25.6) and 6.2\% (95\% CI, 4-9.1), versus 11.3\% (95\% CI, 7.0-16.8) and $1.3 \%$ (95\% CI, 0.2-4.1), respectively, in the CD34+ group $(p=0.006$ and $p=0.01)$. In multivariate analysis, TCD approach was the only parameter with an impact on aGVHD. The cumulative incidence of grade II-IV aGVHD was significantly higher in the ATG group compared with the CD34+ group (HR, 2.05; 95\% CI, 1.12$3.73 ; p=0.02)$. At 1 year, the cumulative incidence of cGVHD and extensive cGVHD were significantly higher in the ATG group, being $27.6 \%$ and $11.3 \%$, versus $2.5 \%$ and $2.5 \%$, respectively, in the CD34+ group $(p<0.0001$ and $p=0.001)$. In multivariate analysis, TCD approach was the only parameter with an impact on cGVHD. The cumulative incidence of cGVHD was significantly higher in the ATG group compared with the CD34+ group (HR, 15.07; 95\% CI, 5.38-42.26; $p<0.0001$ ).

\section{Graft-versus-host disease-free relapse-free survival}

At 2 years, the cumulative incidence of GRFS was significantly lower in the ATG group, being 47.0\% (95\% CI, 41.4$52.5)$ versus $59.1 \%(95 \% \mathrm{CI}, 53.5-68.5)$ in the CD34+ groups $(p=0.003$, Fig. 1d). In multivariate analysis, GRFS was significantly higher in the CD34+ group compared to the ATG group (HR, 1.60; 95\% CI, 1.14-2.23; $p=0.006)$. In addition, cytogenetic status and type of donor were also associated with lower GRFS in multivariate analysis.

\section{Non-relapse mortality}

At 2 years, the cumulative incidence of NRM was $12.1 \%$ (95\% CI, 8.9-15.9) in the ATG group and $17.4 \%$ (95\% CI, 12.0-23.6) in the CD34+ group ( $p=0.16$, Fig. 1e). In multivariate analysis, there was no significant difference in NRM between the ATG and CD34+ groups (HR, 0.96; 95\% CI, 0.54-1.74; $p=0.90)$. The only parameter with a significant impact on NRM incidence in multivariate analysis was patient age: NRM significantly increased in older patients (HR, 1.32; 95\% CI, 1.03-1.68; $p=0.02)$. NRM was related mainly to infection $(n=35)$ and GVHD $(n=19)$, others causes being hemorrhage $(n=2)$, sinusoidal obstruction syndrome (SOS, $n=4)$, cardiac toxicity $(n=1)$, graft failure $(n=2)$, secondary malignancy $(n=2)$, others $(n=13)$, unknown $(n=3)$. Deaths related to infectious complication were significantly more frequent in the CD34+ group (16/28 versus $19 / 53$ in ATG group, $p=$ 
Table 3 Transplant-related events multivariate analysis

\begin{tabular}{|c|c|c|}
\hline Outcome & Hazard ratio (95\% confidence interval) & $p$ value \\
\hline \multicolumn{3}{|l|}{ Overall survival } \\
\hline ATG versus CD34 & $1.43(0.97-2.11)$ & 0.07 \\
\hline Age per 10 years & $1.15(1.00-1.34)$ & 0.047 \\
\hline Poor versus intermediate cytogenetic & $1.16(1.11-2.19)$ & 0.009 \\
\hline Unrelated versus related donor & $1.23(0.86-1.76)$ & 0.27 \\
\hline \multicolumn{3}{|l|}{ Leukemia-free survival } \\
\hline ATG versus CD34 & $1.25(0.88-1.78)$ & 0.21 \\
\hline Age per 10 years & $1.03(0.91-1.17)$ & 0.60 \\
\hline Poor versus intermediate cytogenetic & $1.70(1.26-2.31)$ & 0.0006 \\
\hline Unrelated versus related donor & $1.22(0.88-1.70)$ & 0.23 \\
\hline \multicolumn{3}{|l|}{ Non-relapse mortality } \\
\hline ATG versus CD34 & $0.96(0.54-1.74)$ & 0.90 \\
\hline Age per 10 years & $1.32(1.03-1.68)$ & 0.02 \\
\hline Poor versus intermediate cytogenetic & $1.08(0.62-1.90)$ & 0.77 \\
\hline Unrelated versus related donor & $1.39(0.8-2.42)$ & 0.24 \\
\hline \multicolumn{3}{|l|}{ Relapse } \\
\hline ATG versus CD34 & $1.52(0.96-2.42)$ & 0.07 \\
\hline Age per 10 years & $0.93(0.80-1.08)$ & 0.31 \\
\hline Poor versus intermediate cytogenetic & $2.10(1.46-3.03)$ & $<0.0001$ \\
\hline Unrelated versus related donor & $1.10(0.73-1.67)$ & 0.63 \\
\hline \multicolumn{3}{|l|}{ Grade II-IV acute GVHD } \\
\hline ATG versus CD34 & $2.05(1.12-3.73)$ & 0.02 \\
\hline Age per 10 years & $0.99(0.82-1.18)$ & 0.87 \\
\hline Poor versus intermediate cytogenetic & $0.90(0.56-1.48)$ & 0.66 \\
\hline Unrelated versus related donor & $1.87(1.12-3.09)$ & 0.02 \\
\hline \multicolumn{3}{|l|}{ Chronic GVHD } \\
\hline ATG versus CD34 & $15.07(5.38-42.26)$ & $<0.0001$ \\
\hline Age per 10 years & $1.13(0.94-1.36)$ & 0.21 \\
\hline Poor versus intermediate cytogenetic & $1.07(0.66-1.74)$ & 0.79 \\
\hline Unrelated versus related donor & $1.58(0.97-2.56)$ & 0.07 \\
\hline \multicolumn{3}{|l|}{ GVHD-free relapse-free survival } \\
\hline ATG versus CD34 & $1.60(1.14-2.34)$ & 0.006 \\
\hline Age per 10 years & $1.01(0.90-1.13)$ & 0.88 \\
\hline Poor versus intermediate cytogenetic & $1.65(1.25-2.18)$ & 0.0004 \\
\hline Unrelated versus related donor & $1.42(1.05-1.93)$ & 0.02 \\
\hline
\end{tabular}

Abbreviations: ATG antithymocyte globulin, GVHD graft-versus-host disease

$0.045)$, while there was no difference between groups regarding death related to GVHD (5/28 in CD34+ versus $14 / 53$ in ATG group, $p=0.41$ ).

\section{Donor lymphocyte infusion}

Similar proportions of patients received DLI post-transplant in both cohorts. In the ATG T cell depletion cohort, 38 (10.5\%) patients received DLI for the following indications: mixed chimerism in 8 patients, relapse in 19 patients, and prophylaxis in 11 patients. In the CD34+ cohort, 19 (11.7\%) patients received DLI. The indications were mixed chimerism in 9 patients, relapse in 7 patients, and infection in 3 patients (2 EBV and 1 HHV-6).

\section{Discussion}

The optimal goal of allo-HCT is to mediate graft-versus-tumor effect to achieve cure, while sparing 

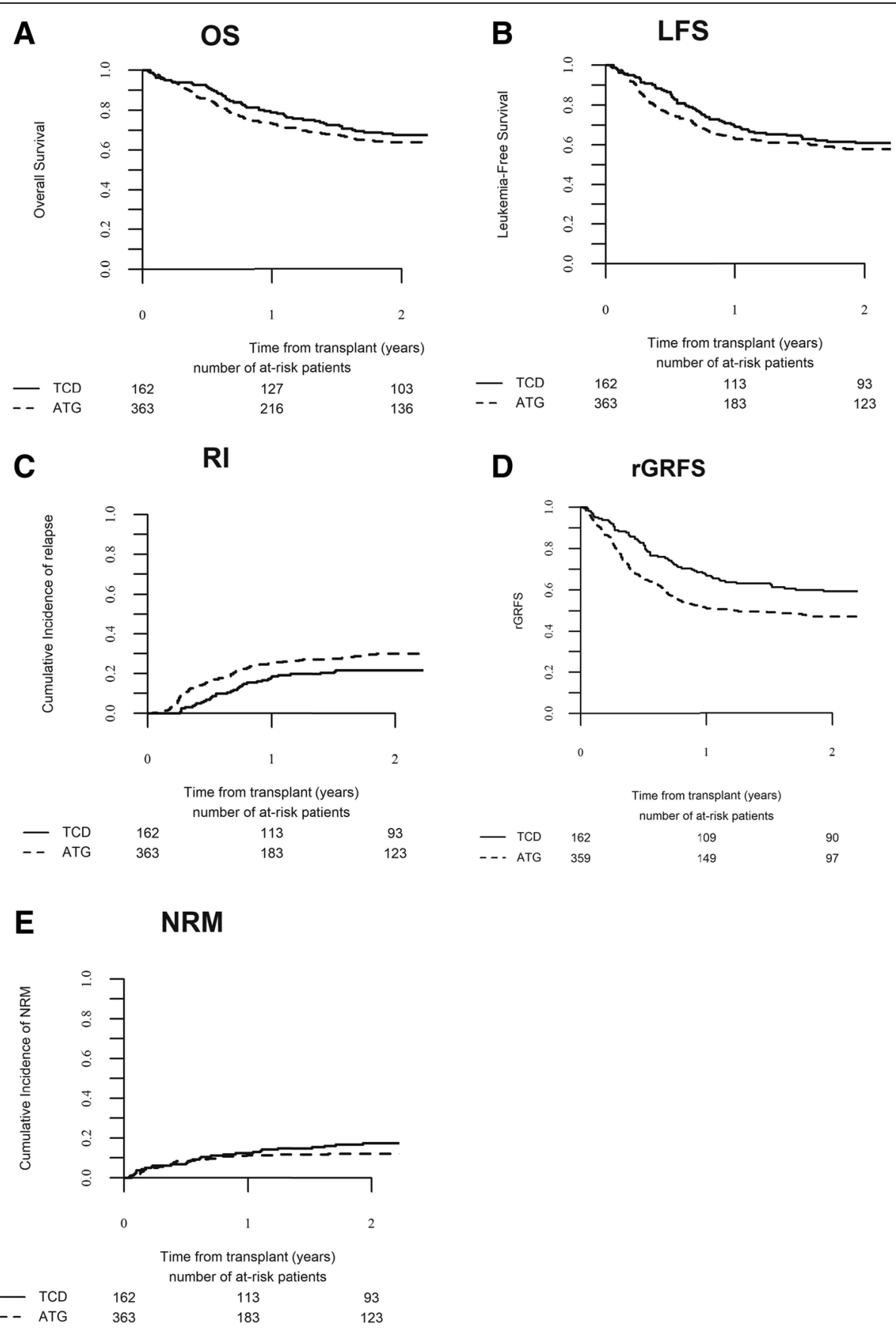

Fig. 1 Outcome after allo-HCT. Overall survival (a), leukemia-free survival (b), cumulative incidence of relapse (c), cumulative incidence of GVHDfree and relapse-free survival (d), and cumulative incidence of non-relapse mortality (e). OS, overall survival; LFS, leukemia-free survival; RI, relapse incidence, rGRFS, refined GVHD-free relapse-free survival; NRM, non-relapse mortality

patients from severe comorbidity. Over the last decade, patients' outcomes have improved significantly with an improved OS and decreased NRM [3]. However, despite this progress, there has been an increase in the incidence of cGVHD, the leading cause of late NRM and morbidity after allo-HCT $[3,6]$, associated with the use of unrelated donors and of PBSC grafts $[4,5]$. Identification of the best strategy for cGVHD prevention is of the utmost importance, and while TCD may be a potential strategy, there remains a concern that it may be at the expense of an increased incidence of relapse. The primary objective of this retrospective study was to assess the relative efficacy of two TCD approaches, in vitro TCD using ATG, and ex vivo TCD with CD34 selection, and showed high OS and LFS with both 
approaches in patients with AML in CR1 transplanted with matched donors after a MAC regimen.

Furthermore, our study confirms that TCD is associated with a low incidence of severe acute and chronic GVHD, with a day 100 cumulative incidence of grade III-IV aGVHD of $6.2 \%$ and $1.3 \%$ and a 1-year cumulative incidence of extensive cGVHD of $11.3 \%$ and $2.5 \%$ in the ATG and the CD34+ groups, respectively. The results in the ATG groups are in accordance with previously published prospective randomized trials, with an incidence of grade III-IV aGVHD ranging from 2.4 to $11.7 \%$ and an incidence of extensive or moderate to severe cGVHD between 5 and 13\% [8-10, 12]. Similarly, in the CD34+ group, the cumulative incidence of severe grade III-IV aGVHD and extensive cGVHD compares favorably to data available from clinical trials. In a prospective randomized trial of ex vivo TCD, Wagner et al. reported a cumulative incidence of grade III-IV aGVHD and overall cGVHD of $19 \%$ and 29\% [29]; however, TCD in that study was limited to 1 to 2 logs depletion. More recently, with the TCD techniques utilized by the MSKCC group that allow 3 to 4 logs of $\mathrm{T}$ cell depletion, Devine et al. reported a cumulative incidence of grade III-IV aGVHD and extensive cGVHD of $4.5 \%$ and $6.8 \%$, respectively, in a multicenter prospective phase 2 trial [15]. Overall progress in ex vivo TCD techniques have achieved a very low incidence of GVHD, leading to a significantly lower cumulative incidence of both acute and chronic GVHD in the CD34+ group, translating in a higher GRFS in those patients. It should be noted that the use of CD34 selection incorporates ATG, which is primarily used to promote engraftment by abrogating host $\mathrm{T}$ cells, but likely has an effect on residual donor $\mathrm{T}$ cells in the CD34-selected graft. This potentially contributes to the low risk of GVHD as well as delayed immune recovery [30]. Finally, use of a matched unrelated donor remains associated with an increase incidence of grade II-IV aGVHD, while there was a trend toward a higher incidence of cGVHD in multivariate analysis, highlighting that TCD, either ex vivo or in vivo, does not completely overcome HLA barrier.

The increased incidence of GVHD seen in the ATG group does not translate in a higher cumulative incidence in NRM in those patients. In fact, there was no difference in the incidence of death related to GVHD between groups (12\% in the ATG versus $10 \%$ in the CD34 groups), while there was more death related to infections in the CD34 group: $30 \%$ versus $17 \%$ in the ATG group. Delayed immune recovery after CD34-selected TCD allo-HCT contributes to an increase incidence of infectious complications, which may result in a lack of improvement in OS despite the low incidence of GVHD, compared to unmodified grafts $[18,30-36]$. However, the median age in the CD34+ group was over a decade older than the ATG group. Age is a known risk factor for GVHD, NRM and delayed immune reconstitution, and the results of the study need to be considered in the context of this significant age difference between the cohorts.

While use of TCD was thought to be associated with an increase incidence of relapse, relapse incidence remains limited in our study, and no difference between groups was observed in multivariate analysis. This observation is probably related to the intensity of the conditioning regimen administered. Indeed, while in four out of six studies that include exclusively RIC regimen, ATG was associated with an increased risk of relapse, in studies that include MAC or MAC and RIC regimens together, no increase in relapse risk was reported [37]. Similarly, the MSKCC group recently reported a lower incidence of relapse using CD34-selected TCD allo-HCT with MAC compared to RIC [38]. In our study, while there were some differences in conditioning regimen between the two groups, all patients received a MAC regimen. Therefore, the incidences of relapse observed in our study are in accordance with previously published studies, despite the inclusion of one third of patients with poor risk cytogenetic status. Unfortunately, due to its retrospective nature being registry-based study, molecular characteristics were not available for all patients and we were not able to refine our analysis based on these parameters. In addition, the inhomogeneity of ATG doses used in our study may have interfered with patients' outcome. Indeed, while lower ATG exposure is thought to be associated with a higher risk of GVHD, high exposure may produce excessive $\mathrm{T}$ cell depletion, leading to delayed immune reconstitution with increased risk of relapse, but also higher NRM, mostly as a result of infections [13]. Therefore, Ayuk et al. reported that use of lower doses of grafalon (30 versus $60 \mathrm{mg} / \mathrm{kg}$ ) was associated with a lower NRM but had no impact on chronic GVHD and relapse rate after MAC allo-HCT [39]. Furthermore, Locatelli et al. evaluated even lower doses of grafalon (15 versus $30 \mathrm{mg} / \mathrm{kg}$ ) in a phase III trial and found that they were associated with an improved OS and progression-free survival without significantly increasing the incidence of GVHD [40]. Finally, ATG pharmacokinetics and pharmacodynamics may also have a significant impact on HCT outcomes. For example, while ATG dose is based on patients' weight, Admiraal et al. recently developed a pharmacokinetic model where absolute lymphocyte count at time of ATG administration was the only relevant predictor for ATG pharmacokinetics in adults [41]. Development of such approaches may help to further improve ATG safety and tolerability.

Our study does have some limitations, due in part to its retrospective nature and potential differences in supportive care. One limitation of our study is that all patients from the CD34+ group were treated in a single center highly experienced in this approach, while the ATG group was constituted from a multicenter-based registry. However, inclusion criteria were defined in order to constitute a cohort of patient as homogeneous as possible, CR1 
AML patients with a matched donor that received rabbit ATG and a Bu-Cy, Bu-Flu, or Cy-TBI MAC regimen, in order to overcome this limitation and to reduce bias due to disease status and donor type on disease outcome.

Another potential limitation is the broader applicability of CD34 selection given the fact that all patients in the CD34 group were from a single center highly experienced in this approach. However, this approach has previously shown similar results in a multicenter phase 2 trial [15]. Furthermore, a randomized multicenter phase 3 trial is currently comparing this approach to post-transplant cyclophosphamide or tacrolimus and methotrexate in patients with acute leukemia and MDS receiving a MAC transplant from an 8/8 HLA-matched related or unrelated donor (NCT02345850).

\section{Conclusions}

Overall, our study shows that NRM, OS, and LFS are similar after ex vivo CD34-selected and in vivo ATG TCD MAC allo-HCT from related/unrelated donors in patients with AML in CR1 and intermediate/high-risk cytogenetic. Notably, the cumulative incidence of acute (total and severe) and chronic GVHD was higher after allo-HCT with ATG, leading to a lower GRFS in those patients. In contrast, stronger immunosuppression in the CD34+ group leads to a higher incidence of infectious related death. Given the high OS seen in patients with AML in CR1 with both approaches, they should be compared in a prospective randomized trial.

\section{Additional file}

Additional file 1: List of EBMT contributing centers by decreasing

number of patients enrolled in the study. (PDF $38 \mathrm{~kb}$ )

\begin{abstract}
Abbreviations
allo-HCT: Allogeneic hematopoietic stem cell transplantation; ALWP: Acute Leukemia Working Party; AML: Acute myeloid leukemia; ATG: Antithymocyte globulin; Bu: Busulfan; CGVHD: Chronic graft-versus-host disease; Cy: Cyclophosphamide; EBMT: European group for Blood and Marrow Transplantation; Flu: Fludarabine; GRFS: GVHD-free relapse-free survival; GVHD: Graft-versus-host disease; HLA: Human leukocyte antigen; HR: Hazard ratio; LFS: Leukemia-free survival; MAC: Myeloablative; MRD: Matched related donor; MSKCC: Memorial Sloan Kettering Cancer Center; NRM: Non-relapse mortality; OS: Overall survival; PBSC: Peripheral blood stem cells; TBI: Total body irradiation; TCD: T cell-depleted; UD: Unrelated donor
\end{abstract}

\section{Funding}

This research was supported in part by National Institutes of Health award number P01 CA23766 and NIH/NCI Cancer Center Support Grant P30 CA008748. The content is solely the responsibility of the authors and does not necessarily represent the official views of the National Institutes of Health.

\section{Availability of data and materials}

The dataset supporting the conclusions of this article are available in the ALWP of EBMT in Paris, 184 rue Faubourg Saint Antoine.

\section{Authors' contributions}

$F M, M L, M M, A N$, and MAP designed the research and/or analyzed the data. $C C, D B, E B P, J P, R O, N M, M M, L V, H C M, Y H, A A J, S F$, and SG provided important clinical data. FM wrote the first draft of the manuscript. All authors approved the final version of the manuscript.

\section{Ethics approval and consent to participate}

This retrospective multicenter analysis was approved by the Acute Leukemia Working Party (ALWP) of the EBMT group registry and the institutional review board of the MSKCC. All patients gave written informed consent for the use of their data.

\section{Consent for publication}

Not applicable.

\section{Competing interests}

The authors declare that they have no competing interests.

\section{Publisher's Note}

Springer Nature remains neutral with regard to jurisdictional claims in published maps and institutional affiliations.

\section{Author details}

'Service d'Hématologie Clinique et Thérapie Cellulaire, AP-HP, Hôpital Saint-Antoine, Paris F-75012, France. ${ }^{2}$ INSERM, Centre de Recherche Saint-Antoine (CRSA), Sorbonne Université, F-75012 Paris, France. ${ }^{3}$ Adult Bone Marrow Transplantation Service, Memorial Sloan Kettering Cancer Center, New York, NY, USA. ${ }^{4}$ Department of Medicine, Weill Cornell Medical College, New York, NY, USA. ${ }^{5}$ Programme de Transplantation \& Therapie Cellulaire, Centre de Recherche en Cancérologie de Marseille, Institut Paoli Calmettes, Marseille, France. ${ }^{6}$ University Hospital, Hematology, Basel, Switzerland. ${ }^{7}$ Bone Marrow Transplant Service, Department of Pediatrics, Memorial Sloan Kettering Cancer Center, New York, NY, USA. ${ }^{8}$ Department of Pediatrics, Weill Cornell Medical College, New York, NY, USA. ${ }^{9} \mathrm{CHU}$ Bordeaux, Hôpital Haut-leveque, Pessac, France. ${ }^{10}$ Stem Cell Transplantation Unit, HUCH Comprehensive Cancer Center, Helsinki, Finland. " Département d'Hématologie Clinique, CHU Lapeyronie, Montpellier, France. ${ }^{12}$ Service des Maladies du Sang, CHRU, Angers, France. ${ }^{13}$ EBMT Paris Study Office/ CEREST-TC, Paris, France. ${ }^{14}$ Hematology Division, Chaim Sheba Medical Center, Tel-Hashomer, Israel. ${ }^{15}$ Adult Bone Marrow Transplantation Service, Department of Medicine, Memorial Sloan Kettering Cancer Center, 1275 York Avenue, Box 298, New York, NY 10065, USA.

Received: 29 June 2018 Accepted: 25 September 2018 Published online: 20 October 2018

\section{References}

1. Dohner H, Weisdorf DJ, Bloomfield CD. Acute myeloid leukemia. N Engl J Med. 2015;373:1136-52.

2. Sengsayadeth S, Savani BN, Blaise D, Malard F, Nagler A, Mohty M. Reduced intensity conditioning allogeneic hematopoietic cell transplantation for adult acute myeloid leukemia in complete remission - a review from the Acute Leukemia Working Party of the EBMT. Haematologica. 2015;100:859-69.

3. Malard F, Chevallier P, Guillaume T, Delaunay J, Rialland F, Harousseau JL, Moreau P, Mechinaud F, Milpied N, Mohty M. Continuous reduced nonrelapse mortality after allogeneic hematopoietic stem cell transplantation: a single-institution's three decade experience. Biol Blood Marrow Transplant. 2014;20:1217-23.

4. Flowers ME, Inamoto Y, Carpenter PA, Lee SJ, Kiem HP, Petersdorf EW, Pereira SE, Nash RA, Mielcarek M, Fero ML, et al. Comparative analysis of risk factors for acute graft-versus-host disease and for chronic graft-versus-host disease according to National Institutes of Health consensus criteria. Blood. 2011;117:3214-9.

5. Anasetti C, Logan BR, Lee SJ, Waller EK, Weisdorf DJ, Wingard JR, Cutler CS, Westervelt P, Woolfrey A, Couban S, et al. Peripheral-blood stem cells versus bone marrow from unrelated donors. N Engl J Med. 2012;367:1487-96.

6. Arai S, Arora M, Wang T, Spellman SR, He W, Couriel DR, Urbano-Ispizua A, Cutler CS, Bacigalupo AA, Battiwalla M, et al. Increasing incidence of chronic graft-versus-host disease in allogeneic transplantation: a report from the Center for International Blood and Marrow Transplant Research. Biol Blood Marrow Transplant. 2015;21:266-74.

7. Bacigalupo A, Lamparelli T, Bruzzi P, Guidi S, Alessandrino PE, di Bartolomeo P, Oneto R, Bruno B, Barbanti M, Sacchi N, et al. Antithymocyte globulin for graft-versus-host disease prophylaxis in transplants from unrelated donors: 2 
randomized studies from Gruppo Italiano Trapianti Midollo Osseo (GITMO). Blood. 2001;98:2942-7.

8. Finke J, Bethge WA, Schmoor C, Ottinger HD, Stelljes M, Zander AR, Volin L, Ruutu T, Heim DA, Schwerdtfeger R, et al. Standard graft-versus-host disease prophylaxis with or without anti-T-cell globulin in haematopoietic cell transplantation from matched unrelated donors: a randomised, open-label, multicentre phase 3 trial. Lancet Oncol. 2009;10:855-64.

9. Walker I, Panzarella T, Couban S, Couture F, Devins G, Elemary M, Gallagher G, Kerr $H$, Kuruvilla J, Lee SJ, et al. Pretreatment with anti-thymocyte globulin versus no anti-thymocyte globulin in patients with haematological malignancies undergoing haemopoietic cell transplantation from unrelated donors: a randomised, controlled, open-label, phase 3, multicentre trial. Lancet Oncol. 2016;17:164-73.

10. Kroger N, Solano C, Wolschke C, Bandini G, Patriarca F, Pini M, Nagler A, Selleri C, Risitano A, Messina G, et al. Antilymphocyte globulin for prevention of chronic graft-versus-host disease. N Engl J Med. 2016;374:43-53.

11. Bacigalupo A, Lamparelli T, Barisione G, Bruzzi P, Guidi S, Alessandrino PE, di Bartolomeo P, Oneto R, Bruno B, Sacchi N, et al. Thymoglobulin prevents chronic graft-versus-host disease, chronic lung dysfunction, and late transplant-related mortality: long-term follow-up of a randomized trial in patients undergoing unrelated donor transplantation. Biol Blood Marrow Transplant. 2006;12:560-5.

12. Soiffer RJ, Kim HT, McGuirk J, Horwitz ME, Johnston L, Patnaik MM, Rybka W, Artz A, Porter DL, Shea TC, et al. Prospective, randomized, double-blind, phase iii clinical trial of anti-T-lymphocyte globulin to assess impact on chronic graft-versus-host disease-free survival in patients undergoing HLAmatched unrelated myeloablative hematopoietic cell transplantation. J Clin Oncol. 2017. https://doi.org/10.1200/JCO.2017.75.8177.

13. Mohty M, Malard F. Antithymocyte globulin for graft-versus-host disease prophylaxis after allogeneic hematopoietic stem-cell transplantation. J Clin Oncol. 2017. https://doi.org/10.1200/JCO.2017.76.0512.

14. Kottaridis PD, Milligan DW, Chopra R, Chakraverty RK, Chakrabarti S, Robinson S, Peggs K, Verfuerth S, Pettengell R, Marsh JC, et al. In vivo CAMPATH-1H prevents graft-versus-host disease following nonmyeloablative stem cell transplantation. Blood. 2000;96:2419-25.

15. Devine SM, Carter S, Soiffer RJ, Pasquini MC, Hari PN, Stein A, Lazarus HM, Linker C, Stadtmauer EA, Alyea EP 3rd, et al. Low risk of chronic graft-versushost disease and relapse associated with T cell-depleted peripheral blood stem cell transplantation for acute myelogenous leukemia in first remission: results of the blood and marrow transplant clinical trials network protocol 0303. Biol Blood Marrow Transplant. 2011;17:1343-51.

16. Papadopoulos EB, Carabasi MH, Castro-Malaspina H, Childs BH, Mackinnon S, Boulad F, Gillio AP, Kernan NA, Small TN, Szabolcs P, et al. T-cell-depleted allogeneic bone marrow transplantation as postremission therapy for acute myelogenous leukemia: freedom from relapse in the absence of graftversus-host disease. Blood. 1998;91:1083-90.

17. Jakubowski AA, Small TN, Kernan NA, Castro-Malaspina H, Collins N, Koehne G, Hsu KC, Perales MA, Papanicolaou G, van den Brink MR, et al. T cell-depleted unrelated donor stem cell transplantation provides favorable disease-free survival for adults with hematologic malignancies. Biol Blood Marrow Transplant. 2011;17:1335-42.

18. Jakubowski AA, Petrlik E, Maloy M, Hilden P, Papadopoulos E, Young JW, Boulad F, Castro-Malaspina H, Tamari R, Dahi PB, et al. T cell depletion as an alternative approach for patients 55 years or older undergoing allogeneic stem cell transplantation as curative therapy for hematologic malignancies. Biol Blood Marrow Transplant. 2017;23:1685-94.

19. Pasquini MC, Devine S, Mendizabal A, Baden LR, Wingard JR, Lazarus HM, Appelbaum FR, Keever-Taylor CA, Horowitz MM, Carter S, et al. Comparative outcomes of donor graft CD34+ selection and immune suppressive therapy as graft-versus-host disease prophylaxis for patients with acute myeloid leukemia in complete remission undergoing HLA-matched sibling allogeneic hematopoietic cell transplantation. J Clin Oncol. 2012;30:3194-201.

20. Jakubowski AA, Small TN, Young JW, Kernan NA, Castro-Malaspina H, Hsu KC, Perales MA, Collins N, Cisek C, Chiu M, et al. T cell depleted stem-cell transplantation for adults with hematologic malignancies: sustained engraftment of HLA-matched related donor grafts without the use of antithymocyte globulin. Blood. 2007;110:4552-9.

21. Bayraktar UD, de Lima M, Saliba RM, Maloy M, Castro-Malaspina HR, Chen J, Rondon G, Chiattone A, Jakubowski AA, Boulad F, et al. Ex vivo T cell-depleted versus unmodified allografts in patients with acute myeloid leukemia in first complete remission. Biol Blood Marrow Transplant. 2013;19:898-903.

22. Keever-Taylor CA, Devine SM, Soiffer RJ, Mendizabal A, Carter S, Pasquini MC, Hari PN, Stein A, Lazarus HM, Linker C, et al. Characteristics of CliniMACS(R) system CD34-enriched T cell-depleted grafts in a multicenter trial for acute myeloid leukemia-Blood and Marrow Transplant Clinical Trials Network (BMT (TN) protocol 0303. Biol Blood Marrow Transplant. 2012;18:690-7.

23. Dohner $H$, Estey EH, Amadori S, Appelbaum FR, Buchner T, Burnett AK, Dombret $\mathrm{H}$, Fenaux P, Grimwade D, Larson RA, et al. Diagnosis and management of acute myeloid leukemia in adults: recommendations from an international expert panel, on behalf of the European LeukemiaNet. Blood. 2010;115:453-74.

24. Peric Z, Cahu X, Chevallier P, Brissot E, Malard F, Guillaume T, Delaunay J, Ayari S, Dubruille V, Le Gouill S, et al. Features of Epstein-Barr virus (EBV) reactivation after reduced intensity conditioning allogeneic hematopoietic stem cell transplantation. Leukemia. 2011;25:932-8.

25. Ruggeri A, Labopin M, Ciceri F, Mohty M, Nagler A. Definition of GvHD-free, relapse-free survival for registry-based studies: an ALWP-EBMT analysis on patients with AML in remission. Bone Marrow Transplant. 2016;51:610-1.

26. Przepiorka D, Weisdorf D, Martin P, Klingemann HG, Beatty P, Hows J, Thomas ED. 1994 Consensus Conference on Acute GVHD Grading. Bone Marrow Transplant. 1995;15:825-8.

27. Filipovich AH, Weisdorf D, Pavletic S, Socie G, Wingard JR, Lee SJ, Martin P, Chien J, Przepiorka D, Couriel D, et al. National Institutes of Health consensus development project on criteria for clinical trials in chronic graftversus-host disease: I. Diagnosis and staging working group report. Biol Blood Marrow Transplant. 2005;11:945-56.

28. Shulman HM, Sullivan KM, Weiden PL, McDonald GB, Striker GE, Sale GE, Hackman R, Tsoi MS, Storb R, Thomas ED. Chronic graft-versus-host syndrome in man. A long-term clinicopathologic study of 20 Seattle patients. Am J Med. 1980;69:204-17.

29. Wagner JE, Thompson JS, Carter SL, Kernan NA, Unrelated Donor Marrow Transplantation Trial. Effect of graft-versus-host disease prophylaxis on 3-year disease-free survival in recipients of unrelated donor bone marrow (T-cell Depletion Trial): a multi-centre, randomised phase II-III trial. Lancet. 2005;366:733-41.

30. Goldberg JD, Zheng J, Ratan R, Small TN, Lai KC, Boulad F, Castro-Malaspina H, Giralt SA, Jakubowski AA, Kernan NA, et al. Early recovery of T-cell function predicts improved survival after T-cell depleted allogeneic transplant. Leuk Lymphoma. 2017;58:1859-71.

31. Kosuri S, Adrianzen Herrera D, Scordo M, Shah GL, Cho C, Devlin SM, Maloy MA, Nieves J, Borrill T, Carlow DC, et al. The impact of toxicities on first-year outcomes after ex vivo CD34(+)-selected allogeneic hematopoietic cell transplantation in adults with hematologic malignancies. Biol Blood Marrow Transplant. 2017:23:2004-11.

32. Scordo M, Shah GL, Kosuri S, Herrera DA, Cho C, Devlin SM, Maloy MA, Nieves J, Borrill T, Avecilla ST, et al. Effects of late toxicities on outcomes in long-term survivors of ex-vivo CD34(+)-selected allogeneic hematopoietic cell transplantation. Biol Blood Marrow Transplant. 2018;24:133-41.

33. Shah GL, Scordo M, Kosuri S, Herrera DA, Cho C, Devlin SM, Borrill T, Carlow DC, Avecilla ST, Meagher RC, et al. Impact of toxicity on survival for older adult patients after CD34(+) selected allogeneic hematopoietic stem cell transplantation. Biol Blood Marrow Transplant. 2018;24:142-9.

34. Cho C, Hsu M, Barba P, Maloy MA, Avecilla ST, Barker JN, Castro-Malaspina H, Giralt SA, Jakubowski AA, Koehne G, et al. Long-term prognosis for 1-year relapsefree survivors of CD34+ cell-selected allogeneic hematopoietic stem cell transplantation: a landmark analysis. Bone Marrow Transplant. 2017;52:1629-36.

35. Huang YT, Kim SJ, Lee YJ, Burack D, Nichols P, Maloy M, Perales MA, Giralt SA, Jakubowski AA, Papanicolaou GA. Co-infections by double-stranded DNA viruses after ex vivo T cell-depleted, CD34(+) selected hematopoietic cell transplantation. Biol Blood Marrow Transplant. 2017;23:1759-66.

36. Huang YT, Neofytos D, Foldi J, Kim SJ, Maloy M, Chung D, Castro-Malaspina H, Giralt SA, Papadopoulos E, Perales MA, et al. Cytomegalovirus infection after CD34(+)-selected hematopoietic cell transplantation. Biol Blood Marrow Transplant. 2016;22:1480-6.

37. Storek J, Mohty M, Boelens JJ. Rabbit anti-T cell globulin in allogeneic hematopoietic cell transplantation. Biol Blood Marrow Transplant. 2015;21:959-70.

38. Barba P, Martino R, Zhou Q, Cho C, Castro-Malaspina H, Devlin S, Esquirol A, Giralt S, Jakubowski AA, Caballero D, et al. cd34+ selection vs. reducedintensity conditioning and unmodified graft for allogeneic hematopoietic cell transplantation in patients with AML and MDS > 50 years. Biol Blood Marrow Transplant. 2018;24:964-72.

39. Ayuk F, Diyachenko G, Zabelina T, Wolschke C, Fehse B, Bacher U, Erttmann R, Kroger N, Zander AR. Comparison of two doses of antithymocyte globulin in patients undergoing matched unrelated donor allogeneic stem cell transplantation. Biol Blood Marrow Transplant. 2008;14:913-9. 
40. Locatelli F, Bernardo ME, Bertaina A, Rognoni C, Comoli P, Rovelli A, Pession A, Fagioli F, Favre C, Lanino E, et al. Efficacy of two different doses of rabbit anti-Tlymphocyte globulin to prevent graft-versus-host disease in children with haematological malignancies transplanted from an unrelated donor: a multicentre, randomised, open-label, phase 3 trial. Lancet Oncol. 2017;18:1126-36.

41. Admiraal R, Nierkens S, de Witte MA, Petersen EJ, Fleurke GJ, Verrest L, Belitser SV, Bredius RGM, Raymakers RAP, Knibbe CAJ, et al. Association between anti-thymocyte globulin exposure and survival outcomes in adult unrelated haemopoietic cell transplantation: a multicentre, retrospective, pharmacodynamic cohort analysis. Lancet Haematol. 2017;4:e183-91.

Ready to submit your research? Choose BMC and benefit from:

- fast, convenient online submission

- thorough peer review by experienced researchers in your field

- rapid publication on acceptance

- support for research data, including large and complex data types

- gold Open Access which fosters wider collaboration and increased citations

- maximum visibility for your research: over $100 \mathrm{M}$ website views per year

At BMC, research is always in progress.

Learn more biomedcentral.com/submissions 